Journal for ImmunoTherapy of Cancer

To cite: Augustin RC, Leone RD, Naing A, et al. Next steps for clinical translation of adenosine pathway inhibition in cancer immunotherapy. Journal for ImmunoTherapy of Cancer 2022;10:e004089. doi:10.1136/ jitc-2021-004089

RB and JJL are joint senior authors.

Accepted 12 January 2022

Check for updates

(c) Author(s) (or their employer(s)) 2022. Re-use permitted under CC BY-NC. No commercial re-use. See rights and permissions. Published by BMJ.

${ }^{1}$ Department of Medicine, University of Pittsburgh, Pittsburgh, Pennsylvania, USA ${ }^{2}$ Bloomberg-Kimmel Institute for Cancer Immunotherapy, Sidney Kimmel Comprehensive Cancer Research Center, Department of Oncology, Johns Hopkins University School of Medicine, Baltimore, Maryland, USA ${ }^{3}$ Department of Investigational Cancer Therapeutics, University of Texas MD Anderson Cancer Center, Houston, Texas, USA

${ }^{4}$ Department of Medicine and Helen Diller Family Comprehensive Cancer Center, University of California San Francisco, San Francisco,

California, USA

${ }^{5}$ UPMC Hillman Cancer Center, Pittsburgh, Pennsylvania, USA

Correspondence to

Dr Jason J. Luke;

lukejj@upmc.edu

\title{
Next steps for clinical translation of adenosine pathway inhibition in cancer immunotherapy
}

\author{
Ryan C. Augustin, ${ }^{1}$ Robert D. Leone (D) , ${ }^{2}$ Aung Naing (D) , ${ }^{3}$ Lawrence Fong, ${ }^{4}$ \\ Riyue Bao (D) , ${ }^{1,5}$ Jason J. Luke (D) ${ }^{1,5}$
}

\section{ABSTRACT}

Increasing evidence supports targeting the adenosine pathway in immuno-oncology with several clinical programs directed at adenosine $\mathrm{A} 2$ receptor (A2AR, A2BR), CD73 and CD39 in development. Through a cyclic-AMP-mediated intracellular cascade, adenosine shifts the cytokine and cellular profile of the tumor microenvironment away from cytotoxic $T$ cell inflammation toward one of immune tolerance. A perpetuating cycle of tumor cell proliferation, tissue injury, dysregulated angiogenesis, and hypoxia promote adenosine accumulation via ATP catabolism. Adenosine receptor (eg, A2AR, A2BR) stimulation of both the innate and adaptive cellular precursors lead to immunosuppressive phenotypic differentiation. Preclinical work in various tumor models with adenosine receptor inhibition has demonstrated restoration of immune cell function and tumor regression. Given the broad activity but known limitations of anti-programmed cell death protein (PD1) therapy and other checkpoint inhibitors, ongoing studies have sought to augment the successful outcomes of anti-PD1 therapy with combinatorial approaches, particularly adenosine signaling blockade. Preliminary data have demonstrated an optimal safety profile and enhanced overall response rates in several early phase clinical trials with A2AR and more recently CD73 inhibitors. However, beneficial outcomes for both monotherapy and combinations have been mostly lower than expected based on preclinical studies, indicating a need for more nuanced patient selection or biomarker integration that might predict and optimize patient outcomes. In the context of known immuno-oncology biomarkers such as tumor mutational burden and interferon-associated gene expression, a comparison of adenosine-related gene signatures associated with clinical response indicates an underlying biology related to immunosuppression, angiogenesis, and T cell inflammation. Importantly, though, adenosine associated gene expression may point to a unique intratumoral phenotype independent from IFN- $\gamma$ related pathways. Here, we discuss the cellular and molecular mechanisms of adenosine-mediated immunosuppression, preclinical investigation of adenosine signaling blockade, recent response data from clinical trials with A2AR, CD73, CD39 and PD1/L1 inhibitors, and ongoing development of predictive gene signatures to enhance combinatorial immune-based therapies.

\section{BACKGROUND: THE ADENOSINE PATHWAY AND IMPLICATIONS FOR TUMORIGENESIS}

Building on the success, but well known limitations, of immune-checkpoint inhibition across tumor types, ${ }^{1}$ rigorous efforts are now underway to identify combinatorial approaches to reverse the immunosuppressive characteristics of the tumor microenvironment (TME). ${ }^{2}$ Phase I-III clinical trials are now assessing the safety and efficacy of anti-programmed cell death 1 (PD-1)/ programmed cell death ligand 1 (PD-L1) augmentation with other checkpoint inhibitors, costimulatory agonists, antiangiogenesis agents, drugs altering the metabolic milieu of the TME and a variety of tumor-specific targeted therapies, among other approaches.

The adenosine signaling pathway has long been studied as an inhibitory neurotransmitter but has also been observed to have anti-inflammatory properties. ${ }^{3}$ The immunomodulatory effects of adenosine were first elucidated nearly 50 years ago while studying cyclic AMP (cAMP) signaling in $\mathrm{T}$ cells $^{45}$; however, the full impact of adenosine on pro-tumor immunity has only been appreciated more recently. Here, we will discuss the cellular and molecular mechanisms underpinning adenosine-mediated immune suppression, preclinical science investigating the immunomodulatory effects of adenosine blockade in the TME, recent clinical trials evaluating adenosine signaling inhibition in combination with other immune-based therapies, and ongoing efforts to identify biomarkers, including tumor genomic signatures, that can inform patient selection and optimal use of adenosine pathway inhibition.

Under physiological conditions, the nucleoside adenosine is present in relatively small concentrations in the extracellular space $(0.05-0.2 \mu \mathrm{M}){ }^{6}$ In the event of tissue injury, ischemia, or cell lysis/death, intracellular ATP is released, representing an inflammatory "beacon" that heralds the invasion of both innate and adaptive immune cells, cytokines, and other signaling molecules. ${ }^{7}$ ATP is rapidly degraded through a set of enzymatic 


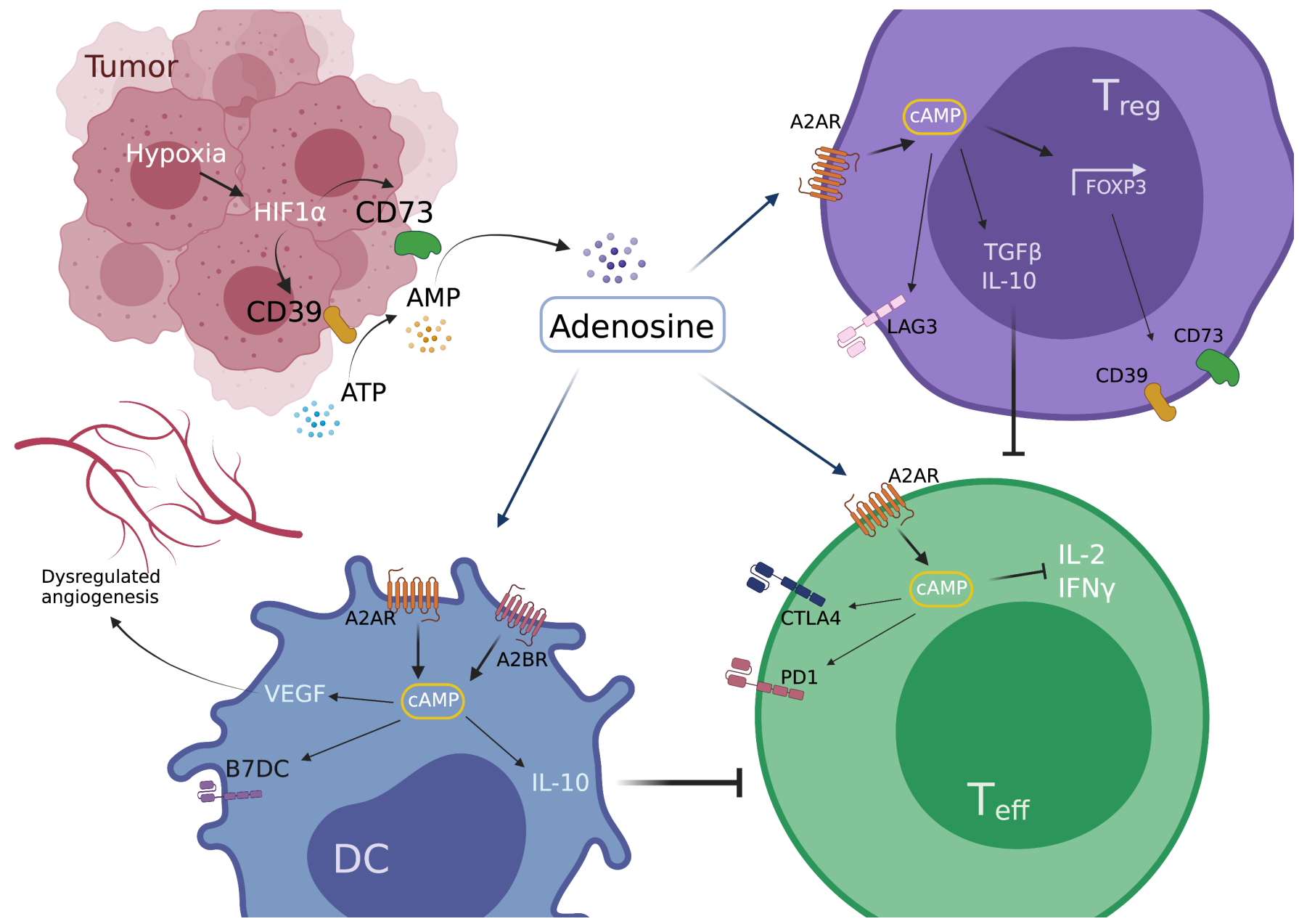

Figure 1 Adenosine-mediated modulation of immune cell function in the tumor microenvironment. IFN, interferon; IL, interleukin.

reactions to adenosine as part of a negative feedback mechanism (figure 1). ${ }^{8}$ The ectonucleotidases, CD39 (ectonucleoside triphosphate diphosphohydrolase-1) and CD73 (ecto-5-prime-nucleotidase; NT5E), catabolize ATP to AMP, and AMP to adenosine, respectively, with the overall effect of promoting intracellular signaling through one of four $G$ protein-coupled receptors (GPCR). ${ }^{7}$ These GPCRs (A1, A2AR, A2BR, A3) exert their effects primarily via cAMP second messenger signaling which can lead to a host of cellular changes. This process is further heightened through hypoxia itself, an element correlated with tissue ischemia and the dysfunctional vascular supply associated with injury, inflammation and tumorigenesis. ${ }^{910}$

Hypoxia, via the hypoxia-inducible factor 1 (HIF1) transcription factor, and other cytokines such as TGF- $\beta$, upregulate CD39 and CD73, further enhancing the adenosine effector pathway. ${ }^{11}$ Additionally, Ma et al showed a significant correlation between HIF1-alpha and A2AR expression in head and neck squamous cell carcinoma (HNSCC tissue). This group also demonstrated the loss of TGFBRI and PTEN tumor suppressor genes increased both A2AR and CD73 expression. ${ }^{12}$ Finally, leukocyte A2AR expression was shown to be upregulated 4-12 hours after tumor necrosis factor (TNF)-alpha or lipopolysaccharide (LPS) exposure. ${ }^{13}$ While this negative feedback mechanism is an important adaptation against autoimmunity and counterproductive tissue remodeling, evidence also associates adenosine signaling with a protumor immunophenotype. ${ }^{14}$

The TME comprises a dynamic milieu of tumor, stromal, endothelial, and immune cells. The adenosine GPCRs can be found on all of these cell types with overarching signaling effects leading to immune tolerance and malignant proliferation. ${ }^{6}{ }^{15}$ Among the mononuclear antigen presenting cells (APC), cytotoxic T cells, regulatory T cells (Treg), and natural killer (NK) cells, research has primarily focused on the high affinity A2A receptor and the low affinity A2B receptor, both of which lead to increased cAMP signaling. ${ }^{16}$ In the myeloid lineage, adenosine-mediated cAMP signaling promotes altered dendritic cell (DC) differentiation leading to a predominant myeloid DC population. ${ }^{17}$ Myeloid DCs promote vascular endothelial growth factor (VEGF)-mediated angiogenesis, matrix remodeling, and immunosuppressive chemokine production. ${ }^{17}$ These anomalous tumor associated macrophages (TAM) decrease IFN- $\gamma$ signaling, inhibit $\mathrm{T}$ cell effector function, and potentiate metastatic tumor growth. ${ }^{18}$ Additionally, A2B signaling promotes the 
expansion of myeloid precursors into immunosuppressive myeloid-derived suppressor cells (MDSC), further potentiating malignant proliferation. ${ }^{19}$ A2AR-mediated cAMP signaling in effector $\mathrm{T}$ cells inhibits proinflammatory cytokine production (eg, IL6, IL-17, IFN- $\gamma$ ), downregulates costimulatory receptors (eg, TCR, CD28), and upregulates molecular checkpoints (eg, PD1, TIM3). ${ }^{6}$ Similar to MDSCs, Treg cells inherently suppress cytotoxicity in the TME; however, Treg cells also upregulate surface CD39, enhancing extracellular adenosine accumulation and further limiting anti-tumor immunity. ${ }^{20}{ }^{21}$ Finally, the innate cytotoxic lymphocytes, NK cells, are also suppressed via A2AR activation, further revealing adenosine's potent and multipronged immunosuppressive effects in the TME. ${ }^{22}$ Accordingly, Young et al showed that A2AR-deficient NK cells led to enhanced maturity, proliferation, and tumor control in a melanoma murine model. $^{23}$

In addition to immune cells, TME-associated endothelial and neoplastic cells also harbor adenosine receptors with differential downstream signaling effects. Not only do endothelial cells express CD39 and CD73, but multiple experiments have demonstrated adenosine-mediated signaling to evoke angiogenesis in the tumor bed. ${ }^{24}$ Additionally, Allard et al showed that A2AR-mediated signaling promoted lymphangiogenesis and associated nodal metastases. ${ }^{25}$ Given that stimulated angiogenesis in the TME can lead to chaotic and dysregulated vasculature, the pro-angiogenic effects of adenosine signaling can paradoxically promote hypoxia and further suppress the anti-tumor immune response. ${ }^{2627}$ Further, tumor cells themselves can also be affected by adenosine signaling but with a more nuanced, heterogeneous response. On one hand, catabolic enzymes leading to the breakdown of adenosine are downregulated in certain tumors, amplifying extracellular adenosine concentration in the TME. ${ }^{28}$ Through A1 and A2A receptors, this increased adenosine has been shown to stimulate cellular proliferation in certain breast cancer models. ${ }^{28}$ Several groups have also demonstrated a MAPK/ERK-dependent process promoting the growth and invasion of certain cancers (including breast, oral, and urothelial) via A2BR stimulation. ${ }^{30-32}$ On the other hand, however, colon cancer and lymphoma models have demonstrated cell cycle arrest when exposed to adenosine via A3 receptor stimulation (the latter exerting its effects through the PI3K pathway as opposed to cAMP). ${ }^{33}$ Thus, while adenosine clearly promotes an immune-tolerant environment, its regulation of cellular proliferation and apoptosis of the tumor itself requires further investigation.

Nearly 50 years ago, researchers first discovered a cAMP-dependent mechanism that could potentially explain the elusive "Hellstrom paradox"-the phenomenon describing cytotoxic T cell suppression in the TME leading to malignant immune evasion. ${ }^{5}$ The adenosine signaling molecule quickly became one of the etiological culprits and rigorous investigation has now centered on further characterizing the adenosine pathway in the
TME. ${ }^{414}$ Importantly, early research failed to identify other cAMP-elevating GPCR signaling pathways that could compensate for A2AR depletion, further enticing researchers to identify possible targets for inhibition in this non-redundant pathway. ${ }^{34}$ These targets included hypoxia and HIF1-alpha, CD39 and CD73 ectonucleotidases, adenosine itself via degrading enzymes, and the A2A/B receptors (the latter already being studied concomitantly in neurological disorders) ${ }^{35} 36$ And while early experiments were promising, several overarching questions remained for pre-clinical investigation: (1) what off-target effects could be expected by inhibiting this abundant signaling molecule, (2) are there are other compensatory pathways, (3) could adenosine serve as a master regulator of other anti-inflammatory pathways, (4) how can we ensure that T cells are even infiltrating the TME to potentially respond to adenosine signaling blockade, and (5) what biomarkers could be used to screen tumors for efficacious therapeutic outcomes?

\section{PRECLINICAL INVESTIGATION}

Building from the seminal observations surrounding adenosine signaling and the immune response to cancer, preclinical work has focused on reversing the immunosuppressive effects of the adenosine pathway in various cancer models. While a majority of experiments have concentrated on the downstream A2A receptor (A2AR), more recent work has also investigated the blockade of more upstream elements (eg, CD39, CD73, hypoxia) with or without A2AR blockade and other checkpoint inhibitors. ${ }^{15} 37$ Given the significant translational potential, initial studies were first directed at better characterizing the immunophenotypic changes to the TME including cytokine profiling and immune cell infiltration in addition to tumor response data. A foundational experiment by Ohta et al found that direct A2AR knockout could significantly decrease tumor growth in a T cell lymphoma murine model. ${ }^{34}$ Furthermore, decreased IFN- $\gamma$ levels seen in this malignant model could be rescued and amplified on pharmacological A2AR inhibition. These beneficial results, however, were found to be dependent on a strong CD8 + T cell infiltration; A2AR inhibition in a nonimmunogenic B16 melanoma model did not result in a significant change in survival. ${ }^{34}$

Shortly thereafter, Waickman et al found similar results in a murine EL4 model with A2AR knockout. ${ }^{38}$ This group subsequently combined the A2AR knockout model with a B7-DC/Fc fusion protein (to antagonize the PD1-B7/ H1 inhibitory interaction)-the additional PD1-axis checkpoint inhibitor further augmented tumor regression and survival. Combinatorial approaches rapidly escalated across multiple groups to assess the effects of A2AR blockade with anti-PD1 and other agents. In 2015, researchers demonstrated synergistic effects with A2AR knockout and PD1 blockade in not only breast and colon cancer models but also a metastatic murine model. ${ }^{39}$ This latter result corroborates prior research showing CD73 
playing a critical role in the migration of tumor cells via extracellular matrix (ECM) adhesion. ${ }^{4041}$

In order to better characterize the relationship between the adenosine and PD1 pathways for more effective coinhibitory options, A2AR expression was measured in $\mathrm{T}$ cells exposed to PD1 blockade. ${ }^{39}$ While anti-PD1 lead to marked increase in A2AR expression as a compensatory immunosuppressive feedback mechanism, the opposite was not true. Leone $e t$ alstudied the effects of PD1 expression on A2AR blockade which showed an overall decrease in PD1 expression along with other checkpoint pathways (eg, LAG3, FoxP3). ${ }^{42}$ Consistently, A2AR blockade lead to a robust increase in IFN- $\gamma$, the effective $\mathrm{T}$ cell transcriptional factor T-bet, and the costimulatory molecule 4-1BB. Importantly, these results point to the adenosine pathway as a central regulator for other checkpoint processes. They also validate prior work by Ngiow et al showing a reduction in CD8 + T cell PD1 levels is necessary to achieve a response to anti-PD1 therapy. ${ }^{43}$ Thus, A2AR inhibition may help achieve this therapeutic threshold, unlocking the benefits of PD1 blockade through this synergistic approach.

With the elucidation of the full adenosine pathway, a multitude of combinatorial therapeutic approaches have now been studied in the preclinical setting. As briefly mentioned above, CD39 and CD73 are highly expressed on the surface of Treg cells, increase extracellular adenosine concentration, and potentiate Treg activity. ${ }^{21}$ Additionally, Samanta et alshowed that traditional chemotherapy can induce CD47, CD73, and PDL1 expression in triple-negative breast cancer cells, serving as a potential escape mechanism in this immune-evasive model. Based on this physiology, Stagg et al inoculated CD73 deficient mice with colon, breast, melanoma, and lymphoma cell lines. ${ }^{40}$ Not only was tumor growth significantly decreased as compared with wild-type mice for each malignancy, but CD73 expressing Treg cells were specifically found to recapture tumor growth, highlighting the important relationship between the adenosine pathway and the immune tolerant Treg activity. ${ }^{40}$ Given the success of antiCD73 monotherapy, combination studies with PD1 and CTLA4 blockade were also investigated. ${ }^{44}$ While a reduction in tumor growth was augmented in the combination cohorts, this effect was lost in IFN-gamma deficient mice, further supporting the critical role of an inflamed TME towards successful immune based therapy. ${ }^{44}$ CD39 was also targeted in a melanoma murine model resulting in similar, although marginal survival benefits. ${ }^{45}$ Even more intriguing, though, was the reduction in endothelial growth along with the lack of Treg-dependent tumor growth and evasion in CD39 deficient mice. This latter effect associated NK-mediated tumor control with Tregdependent suppression-when wild-type NK cells alone or in combination with CD39-deficient Treg cells were infused, tumor regression was achieved; however when wild-type Treg cells were combined with NK cells the tumors progressed. Overall, this experiment highlights the dual role of CD39 blockade: reducing extracellular adenosine production and counteracting Treg-mediated immunosuppression in the TME. ${ }^{45}$ Additionally, CD39 blockade has the added potential of not only limiting downstream adenosine but also accruing ADP and ATP precursors linked to proinflammatory immune activity. ${ }^{46}$ Finally, researchers asked whether dual adenosine pathway inhibition could augment tumor control or simply add redundancy or toxicity. Because A2AR deficient mice were shown to upregulate $\mathrm{CD} 73$ expression, anti-CD73 antibodies were administered alongside an A2AR inhibitor (SCH58261) in a metastatic B16F10 murine model. Dual CD72/A2AR blockade led to significantly decreased disease burden as compared with monotherapy, with beneficial effects dependent on IFN-gamma, NK, and T cell infiltration. ${ }^{47}$

The addition of adenosine pathway antagonists has not only been studied alongside checkpoint blockade but also targeted therapy. In $\mathrm{BRAF}^{\mathrm{V} 600 \mathrm{E}}$-mutant melanoma, early phase trials combining vemurafenib with ipilimumab resulted in severe toxicity. ${ }^{49}$ Additionally, Young et al showed that CD73 expression was highly correlated with aggressive disease in patients with $\mathrm{BRAF}^{\mathrm{V} 600 \mathrm{E}}$ mutant disease. ${ }^{50}$ Thus, providing immune stimulation via adenosine antagonism could be a more promising augmentation strategy alongside BRAF/MEK inhibitors. Accordingly, a melanoma murine model treated with both BRAF/MEK and A2AR antagonists showed significantly less metastatic activity as compared with BRAF/ MEK blockade alone. ${ }^{50}$ Future trials will be needed to evaluate both clinical efficacy and adverse effects with this combinatorial approach.

While a majority of research has thus far focused on discrete, targetable elements of the adenosine pathway, the TME is still often plagued by dysregulated angiogenesis, ischemia, and hypoxia that can further perpetuate adenosine accumulation and immunosuppression. ${ }^{51}$ Hatfield et al sought to target hypoxia itself in a pulmonary tumor model. ${ }^{52}$ On administration of continuous $60 \% \mathrm{FiO}_{2}$, a stark regression in tumors was observed as compared with the normoxic cohort. This differential response was lost, however, on depletion of intratumoral CD4+, CD8+, and NK cells. ${ }^{52}$ Furthermore, characterization of the infiltrating $\mathrm{T}$ cells found a significant decrease in Treg associated FoxP3, CD39, and CD73. Finally, connecting back to the end of the adenosine pathway, A2AR-deficient models exposed to hyperoxia did not exhibit a significant change in tumor regression as compared with normoxic models. This provides further evidence that the adenosine pathway plays a critical role in potentiating immune tolerance and tumor progression.

As alluded to above, other barriers to efficacious adenosine signaling blockade include the paucity of infiltrating lymphocytes along with the rapid deterioration of an ATP-mediated proinflammatory state in the TME. ${ }^{46}$ To address the former, Ohta et al studied the effects of adoptive $\mathrm{T}$ cell transfer on A2AR blockade in a lung metastasis model. ${ }^{34}$ Notably, tumor regression was only seen in the cohort with sufficient 
TIL levels exposed to A2AR inhibition, providing evidence for appropriate screening thresholds along with potential adjunctive therapy alongside A2AR blockade. In an effort to potentiate the ATP-mediated proinflammatory state of the TME, Perrot et al used traditional chemotherapy in a CD39 knockout fibrosarcoma model. ${ }^{46}$ As compared with wild type mice, CD39 deficiency led to significantly reduced tumor growth and improved survival, an effect further augmented by PD1 inhibition. Overall, by blocking the hydrolysis of ATP on release from chemotherapyinduced cell death, an immunogenic TME can be preserved for more effective tumor control. ${ }^{53} 54$ Lastly, Wang et al recently investigated the role of adenosine deaminase 2 (ADA2) as a therapeutic route towards adenosine depletion. PEGylated ADA2 was shown to stimulate $\mathrm{T}$ cell proliferation, promote tumor infiltration, and inhibit tumor growth in both colon and breast cancer murine models. ${ }^{55}$

As we move to translate these concepts into clinical trials, several questions remain. First, what are the effects of adenosine inhibition on the other receptor signaling pathways? While A2AR, and to a lesser extent A2BR, have been studied, the downstream consequences of reduced A1R and A3R signaling are less clear. Further, Cekic et al actually showed A2AR deficiency could impair $\mathrm{T}$ cell maintenance and memory differentiation, likely via reduced IL-7 signaling. ${ }^{56}$ Second, the variety of different immune cells in the TME have a range of both anti-tumor and immune tolerant functionality-parsing out the specific effects of adenosine pathway inhibition on individual cell types will be critical. Notably, recent work has demonstrated tumor regression with DC-specific CD73 blockade, CD73 inhibition in tumors rich with cancer-associated fibroblasts, and APC-specific A2BR blockade ${ }^{57-59}$ This latter finding suggests the possibility of an expanded repertoire of adoptive cellular therapy with immunostimulatory adjuncts. Third, while A2A serves as a nonredundant cAMP-inducing GPCR signaling cascade, other cAMP-mediated pathways (eg, prostaglandin E2, PGE2) should also be investigated. ${ }^{60}$ Bottcher $e t$ al specifically assessed the impact of tumor-derived PGE2 on infiltrative DCs. ${ }^{61}$ In this melanoma model, PGE2 led to a decrease in DC-mediated chemoattractants and NK viability, suggesting a therapeutic target in reversing COX-mediated immunosuppression in the TME. ${ }^{6162}$ Finally, the aforementioned mechanism of adenosine generation may be oversimplified. For example, further characterization of the ectoenzymes CD38 and CD203a have uncovered an additional avenue by which AMP is produced via the degradation of NAD+ and ADPR, respectively. ${ }^{63}{ }^{64}$ ENPP1 has been shown to hydrolyze the STING ligand, cGAMP, simultaneously promoting adenosine accumulation and limiting STING-dependent innate immune pathways. ${ }^{65}$ Increased CD38 expression has been associated with enhanced MDSC and Treg activity in both hematologic and solid cancers along with PD1/PDL1 resistance through its immunosuppressive adenosinergic signaling. ${ }^{6-68}$ Though overall promising, the preclinical data mentioned above will need to be interpreted through appropriate biomarker and genotypic screening modalities to identify efficacious combinatorial regimens for successful patient outcomes in the clinical setting.

\section{CLINICAL DATA AND BIOMARKER INVESTIGATION}

The current era of immunotherapy is now focused on the integration of novel agents with standard of care checkpoint blockade with or without chemotherapy or targeted agents. As we discuss specific adenosine pathway inhibitors in the clinical setting, however, it is important to first contextualize the aforementioned biology with current principles of immunotherapy response. The foundational checkpoint inhibitors are designed to prevent $\mathrm{T}$ cell anergy in the TME; however, these infiltrating lymphocytes still depend on neoantigenicity to evoke an adaptive immune response. ${ }^{69}$ Biomarkers for neoantigenicity include tumor mutational burden (TMB), but more novel genetic signatures associated with a $\mathrm{T}$ cell inflamed (Tinfl) TME have provided additional, comprehensive screening tools. ${ }^{70}$ Previous studies have found a direct correlation between both increased TMB and Tinfl gene expression scores and anti-PD1 response across most tumor types. ${ }^{71}$ While these two biomarkers do not necessarily overlap, indicating a more nuanced connection among mutational burden, neoantigen detection, and $\mathrm{T}$ cell infiltration, the predictive utility of a $\mathrm{T}$ cell inflamed TME remains strong. ${ }^{72}$ Spranger et al studied the relationship between intratumoral cytotoxic $\mathrm{T}$ cell infiltration and immunoregulatory pathways including PD-L1, IDO and FoxP3 Treg cells. ${ }^{73}$ Not only were these suppressive markers dependent on $\mathrm{T}$ cell infiltration, but IFN- $\gamma$ signaling appeared to drive their development, providing a link between lymphocyte invasion, chemokine profiling, and the development of immune tolerant pathways. Using this relationship, Ayers et al compared an IFN- $\gamma$ based signature score with survival outcomes in patients with melanoma undergoing anti-PD1 therapy. ${ }^{74}$ Unsurprisingly, significantly improved outcomes were seen in patients with elevated Tinfl expression scores, providing an important predictive tool for checkpoint blockade.

Given the importance of the inflammatory $\mathrm{T}$ cell response and the deleterious effect of adenosine signaling described above, a burgeoning collection of adenosine pathway inhibitors have entered clinical trials. Primarily targeting the downstream receptors, A2AR and A2BR (table 1A), more recent trials have expanded to CD73 (table 1B) and CD39 blockade (table 1C). Results from early phase trials point to a modest but consistent $~ 5 \%$ overall response rate (ORR) with A2AR monotherapy and up to $\sim 15 \%$ in combination trials. A smaller set of CD73 and CD39 inhibitors have entered clinical trials 
Table 1 (A) A2AR antagonists under clinical investigation; (B) CD73 antagonists under clinical investigation; (C) CD39 antagonists under clinical investigation

\begin{tabular}{|c|c|c|c|c|c|c|}
\hline \multicolumn{7}{|c|}{ (A) A2AR antagonists under clinical investigation } \\
\hline Pharmaceutical & Drug & Clinical Trial & Citation & Drug combinations & Indication & Outcomes \\
\hline \multirow[t]{6}{*}{ Coruvs } & Ciforadenant & $\begin{array}{l}\text { MORPHEUS phase } \\
1 \mathrm{~b} / 2\end{array}$ & $\begin{array}{l}\text { ESMO poster } \\
\# 1315 \mathrm{P}\end{array}$ & Atezolizumab; SOC & NSCLC & $\begin{array}{l}\text { ORR: } 18.2 \% \\
(n=11)\end{array}$ \\
\hline & (CPI-444) & $\begin{array}{l}\text { Phase 1/1b: } \\
\text { NCT02655822 }\end{array}$ & Fong et al & Atezolizumab & Advanced RCC & $\begin{array}{l}\text { ORR: } 3 \%(n=33) \\
\text { (mono) }\end{array}$ \\
\hline & & & $\begin{array}{l}\text { Cancer Disc. } \\
2020\end{array}$ & & & $\begin{array}{l}\text { ORR: } 11 \% \\
(n=35)(\text { combo) }\end{array}$ \\
\hline & & & $\begin{array}{l}\text { ASCO } 2020 \\
\text { poster \#94 }\end{array}$ & & & $\begin{array}{l}\text { Tumor } \\
\text { regression } \\
\text { observed in } \\
6 / 10 \text { CD } 68+\text { pts } \\
(n=3 \text { mono; } n=3 \\
\text { combo) }\end{array}$ \\
\hline & & $\begin{array}{l}\text { Phase 1b: } \\
\text { NCT04280328 }\end{array}$ & & Daratumumab & $\begin{array}{l}\text { Relapsed or } \\
\text { refractory MM }\end{array}$ & $\begin{array}{l}\text { Est. completion: } \\
7 / 2025\end{array}$ \\
\hline & & $\begin{array}{l}\text { Phase 1/1b: } \\
\text { NCT03454451 }\end{array}$ & & $\begin{array}{l}\text { CPI-006 (anti-CD73); } \\
\text { pembrolizumab }\end{array}$ & $\begin{array}{l}\text { Advanced } \\
\text { cancers }\end{array}$ & $\begin{array}{l}\text { Est. completion: } \\
12 / 2023\end{array}$ \\
\hline \multirow[t]{3}{*}{ AstraZeneca } & $\begin{array}{l}\text { Imaradenant } \\
\text { (AZD4635) }\end{array}$ & $\begin{array}{l}\text { Phase 1: } \\
\text { NCT02740985 }\end{array}$ & $\begin{array}{l}\text { JCO abstract } \\
\# 5518\end{array}$ & Durvalumab (anti-PD-L1) & mCRPC & $\begin{array}{l}\text { ORR } 6.1 \% \\
(n=33) \text { (mono) }\end{array}$ \\
\hline & & & & & & $\begin{array}{l}\text { ORR } 16.2 \% \\
(\mathrm{n}=37)(\mathrm{combo})\end{array}$ \\
\hline & & $\begin{array}{l}\text { Phase 1b/2: } \\
\text { NCT03381274 }\end{array}$ & & Oleclumab (anti-CD73) & NSCLC (EGFRm) & Discontinued \\
\hline \multirow{5}{*}{ Arcus } & & $\begin{array}{l}\text { Phase } 1 \mathrm{~b} / 2 \text { : } \\
\text { NCT04660812 } \\
\text { (ARC-9) }\end{array}$ & $\begin{array}{l}\text { JCO } \\
\text { Abstract } \\
\text { \#TPS150 }\end{array}$ & $\begin{array}{l}\text { Zimberelimab (anti-PD1), } \\
\text { bevacizumab (anti- } \\
\text { VEGF) }\end{array}$ & mCRC & $\begin{array}{l}\text { Est. completion: } \\
12 / 2023\end{array}$ \\
\hline & & $\begin{array}{l}\text { Phase 1: } \\
\text { NCT03629756 }\end{array}$ & & Zimberelimab & $\begin{array}{l}\text { Advanced RCC; } \\
\text { mCRPCP }\end{array}$ & $\begin{array}{l}\text { Est. completion: } \\
\text { 9/2021 }\end{array}$ \\
\hline & & $\begin{array}{l}\text { Phase 2: } \\
\text { NCT04262856 } \\
\text { (ARC-7) }\end{array}$ & & $\begin{array}{l}\text { Zimberelimab, } \\
\text { domvanalimab (anti- } \\
\text { TIGIT) }\end{array}$ & NSCLC & $\begin{array}{l}\text { Est. completion: } \\
6 / 2022\end{array}$ \\
\hline & & $\begin{array}{l}\text { Phase 1/1b: } \\
\text { NCT03846310 } \\
\text { (ARC-4) }\end{array}$ & & $\begin{array}{l}\text { Chemo, pembrolizumab } \\
\text { or zimberelimab }\end{array}$ & EGFRm NSCLC & $\begin{array}{l}\text { Est. completion: } \\
2 / 2023\end{array}$ \\
\hline & & $\begin{array}{l}\text { Phase 1b/2: } \\
\text { NCT04381832 } \\
\text { (ARC-6) }\end{array}$ & & Zimberelimab, SOC & mCRPC & $\begin{array}{l}\text { Est. completion: } \\
\text { 10/2023 }\end{array}$ \\
\hline
\end{tabular}

Continued 
Table 1 Continued

(A) A2AR antagonists under clinical investigation

\begin{tabular}{|c|c|c|c|c|c|c|}
\hline Pharmaceutical & Drug & Clinical Trial & Citation & Drug combinations & Indication & Outcomes \\
\hline \multirow[t]{2}{*}{ Novartis } & NIR178 & $\begin{array}{l}\text { Phase 2: } \\
\text { NCT03207867 }\end{array}$ & & PDR001 (anti-PD1) & $\begin{array}{l}\text { Advanced } \\
\text { cancers }\end{array}$ & $\begin{array}{l}\text { Est. completion: } \\
6 / 2022\end{array}$ \\
\hline & & $\begin{array}{l}\text { Phase1 1/2: } \\
\text { NCT02403193 }\end{array}$ & $\begin{array}{l}\text { JCO abstract } \\
\# 9089 \text { (2018) }\end{array}$ & Monotherapy & Advanced NSCLC & $\begin{array}{l}\text { ORR: } 8.3 \% \\
(n=24)\end{array}$ \\
\hline \multirow[t]{2}{*}{ iTEOS } & EOS100850 & $\begin{array}{l}\text { Phase 1/1b: } \\
\text { NCT03873883 }\end{array}$ & & Pembrolizumab & $\begin{array}{l}\text { Advanced } \\
\text { cancers }\end{array}$ & $\begin{array}{l}\text { Est. completion: } \\
12 / 2022\end{array}$ \\
\hline & Inupadenant & $\begin{array}{l}\text { Phase 1: } \\
\text { NCT02740985 }\end{array}$ & $\begin{array}{l}\text { JCO abstract } \\
\text { \#2562 (2021) }\end{array}$ & Monotherapy & $\begin{array}{l}\text { Advanced } \\
\text { cancers }\end{array}$ & $\begin{array}{l}\text { ORR: } 4.8 \% \\
(n=42)\end{array}$ \\
\hline Incyte & INCB106385* & $\begin{array}{l}\text { Phase 1: } \\
\text { NCT04580485 }\end{array}$ & & $\begin{array}{l}\text { INCMGA00012 (anti- } \\
\text { PD1) }\end{array}$ & $\begin{array}{l}\text { Advanced } \\
\text { cancers }\end{array}$ & $\begin{array}{l}\text { Est. completion: } \\
7 / 2023\end{array}$ \\
\hline
\end{tabular}

(B) CD73 antagonists under clinical investigation

\begin{tabular}{|c|c|c|c|c|c|c|}
\hline Pharmaceutical & Drug & Clinical Trial & Citation & Drug combinations & Indication & Outcomes \\
\hline \multirow[t]{5}{*}{ AstraZeneca } & $\begin{array}{l}\text { Oleclumab } \\
\text { (MEDI9447) }\end{array}$ & $\begin{array}{l}\text { Phase 1b/2: } \\
\text { NCT03381274 }\end{array}$ & AACR 2021 & Osimertinib & NSCLC (EGFRm) & $\begin{array}{l}\text { ORR: } 23.1 \% \\
\text { (combo) }\end{array}$ \\
\hline & & & & & & $(n=26)$ \\
\hline & & $\begin{array}{l}\text { Phase 1/1b: } \\
\text { NCT02503774 }\end{array}$ & ASCO 2021 & Durvalumab & $\begin{array}{l}\text { Advanced } \\
\text { cancers }\end{array}$ & $\begin{array}{l}\text { ORR: } 5.5 \% \\
\text { (combo) }\end{array}$ \\
\hline & & & & & & $(n=126)$ \\
\hline & & NCT03822351 & & & & $(n=60)$ \\
\hline \multirow[t]{2}{*}{ I-MAB (Tracon) } & Uliledlimab & $\begin{array}{l}\text { Phase 1: } \\
\text { NCT03835949 }\end{array}$ & ASCO 2021 & Atezolizumab & $\begin{array}{l}\text { Advanced } \\
\text { cancers }\end{array}$ & $\begin{array}{l}\text { ORR: } 23.1 \% \\
\text { (combo) }\end{array}$ \\
\hline & & & & & & $(n=13)$ \\
\hline Corvus & $\begin{array}{l}\text { Mupadolimab } \\
\text { (CPI-006) }\end{array}$ & Phase 1/1b: NCT03 & 454451 & $\begin{array}{l}\text { Ciforadenant } \\
\pm \text { pembrolizumab }\end{array}$ & $\begin{array}{l}\text { Advanced } \\
\text { cancers }\end{array}$ & $\begin{array}{l}\text { Est completion: } \\
12 / 2023\end{array}$ \\
\hline BMS & BMS-986179 & Phase 1/2a: NCT027 & 754141 & Nivolimuab & $\begin{array}{l}\text { Advanced } \\
\text { cancers }\end{array}$ & $\begin{array}{l}\text { Est completion: } \\
2 / 2023\end{array}$ \\
\hline Novartis/surface & $\begin{array}{l}\text { NZV930 } \\
\text { (SRF373) }\end{array}$ & Phase 1/1b: NCT035 & 549000 & Anti-PD1 \pm NIR178 & $\begin{array}{l}\text { Advanced } \\
\text { cancers }\end{array}$ & $\begin{array}{l}\text { Est completion: } \\
2 / 2022\end{array}$ \\
\hline Akesobio & AK119 & Phase 1/1b: NCT045 & 572152 & AKI104 & $\begin{array}{l}\text { Advanced } \\
\text { cancers }\end{array}$ & $\begin{array}{l}\text { Est completion: } \\
1 / 2022\end{array}$ \\
\hline Symphogen & SYM024 & Phase 1: NCT04672 & 434 & SYM021 & $\begin{array}{l}\text { Advanced } \\
\text { cancers }\end{array}$ & $\begin{array}{l}\text { Est completion: } \\
3 / 2024\end{array}$ \\
\hline
\end{tabular}


Table 1 Continued

(C) CD39 antagonists under clinical investigation

\begin{tabular}{llllll}
\hline Pharmaceutical & Drug & Clinical Trial & Drug combinations & Indication & Outcomes \\
\hline Tizona & TTX-030 & Phase 1/1b: NCT04306900 & $\begin{array}{l}\text { Budigalimab, } \\
\text { pembrolizumab }\end{array}$ & $\begin{array}{l}\text { Advanced } \\
\text { cancers }\end{array}$ & $\begin{array}{l}\text { Est. completion: } \\
12 / 2022\end{array}$ \\
Innate & IPH5201 & Phase 1: NCT04261075 & $\begin{array}{l}\text { Durvalumab } \pm \text { oleclumab } \\
\text { Advanced } \\
\text { cancers }\end{array}$ & $\begin{array}{l}\text { Est. completion: } \\
2 / 2023\end{array}$ \\
Surface & SRF617 & Phase 1: NCT04336098 & Pembrolizumab & $\begin{array}{l}\text { Advanced } \\
\text { cancers }\end{array}$ & $\begin{array}{l}\text { Est. completion } \\
11 / 2022\end{array}$ \\
\hline
\end{tabular}

*, A2AR \& A2BR antagonist ; NSCLC, non-small cell lung cancer; ORR, overall response rate; RCC, renal cell carcinoma.

with a wide range of response rates and number of participating patients. While the largest trial of oleclumab (anti-CD73) \pm durvalumab (NCT02503774) showed only marginally improved ORR, ${ }^{75}$ more recent results from the randomized phase 2 COAST trial in stage III nonsmall cell lung cancer (NSCLC) revealed a promising ORR close to $40 \%$ in the dual CD73/PDL1 blockade arm with statistically improved 10-month PFS (64.8 vs 39.2) as compared with anti-PDL1 alone (table $1 \mathrm{~B}) .{ }^{76}$ Of note, since EGFR mutant NSCLC has been shown to upregulate CD73 as a putative immune escape mechanism, oleclumab has also been studied alongside the EGFR inhibitor osmiterinib in NSCLC. ${ }^{77}$ Additionally, rates of dose-limiting toxicity in these trials have been extremely low, making these drugs even more suitable for combinatorial therapies. Finally, interpretation of the modest benefits mentioned above should be contextualized with the respective patient cohorts. A vast majority of these early phase trials only recruited patients with refractory disease, most progressing past second or third lines of therapy, and many with anti-PD1 resistance. Thus, improved response to dual adenosine plus checkpoint blockade could be expected in certain patients if offered as primary therapy.

The most frequently studied cancers in trials of adenosine pathway inhibitors to date include NSCLC, melanoma, renal cell carcinoma (RCC), and metastatic castrate resistant prostate cancer (mCRPC) - adenosine blockade has at least modest monotherapy activity in each of these malignancies. And while it is tempting to collectively describe the immune-mediated therapy across the group, each cancer type may have a unique set of biological processes that determine responsiveness to adenosine blockade. For example, prostate cancer, which has had limited success with anti-PD1 therapy, has been shown to have an extensive set of adenosine-producing enzymes apart from CD39 and CD73, including prostatic acid phosphatase (PAP), alkaline phosphatase and CD38. ${ }^{15}$ This latter enzyme has also been studied in melanoma tumors and, in combination with CD203a and CD73, has been shown to lead to extracellular adenosine generation through NAD+hydrolysis (as opposed to ATP catabolism). ${ }^{78}$ Additionally in RCC, hypoxia-induced HIF1 transcriptional regulation (exacerbated by mutant von Hippel-Lindau protein) can induce CD39 and CD73 activity, leading to further adenosine-mediated immune tolerance. ${ }^{79-81}$ Finally, differential expression of immunosuppressive cytokines (eg, TGF- $\beta$ ) along with infiltration of regulatory MDSC and TAM cells can further disrupt the immune landscape. ${ }^{7}$ Thus, while the adenosine pathway may be constitutively active in most tumors, identifying cancer-specific pathologic markers will be critical in achieving more effective response rates while targeting this pathway.

The clinical results presented thus far have shown both monotherapy benefit along with combinatorial success alongside PD1, targeted, and dual-adenosine pathway inhibitors. However, the response rates have been relatively modest prompting further investigation to better characterize both the genomic signatures and phenotypic markers linked to therapeutic success. A previous study by Trujillo et al found that immunotherapy-relevant genes were positively correlated with PD-L1 levels across the cancer genome atlas (TCGA) cancer types. ${ }^{82}$ Recognizable genes in the PD-L1 correlated cluster include CTLA4, TIGIT, LAG3, and CD8A, while non-PD-L1 correlated genes include VEGFA and TGF- $\beta$. Interestingly, when we integrated genes known to regulate the adenosine pathway into this model, all but one were associated with the non-PD-L1 correlated cluster (figure 2). This is an important finding as most checkpoint inhibitors are primarily effective in PD-L1 expressing tumors at baseline. Conversely, this adenosine expression data may point to a markedly different intratumoral phenotype that no longer depends on IFN- $\gamma$ related pathways.

To further expand this concept, assessment of genomic signatures from a recent clinical trial of patients with RCC treated with A2AR \pm PD-L1 blockade could be informative. In this work by Fong et al an "AdenoSig" gene signature was identified-a collection of genes with significantly induced expression on administration of an adenosine agonist (CXCL1, 2, 3, 4, 5, ILB, IL1B, PTGS2). ${ }^{83}$ When comparing this signature with response rates to adenosine blockade, a preliminary correlation was identified, indicating the AdenoSig score may predict response to A2AR inhibitors, at least in RCC. Notably, this signature was found to be a negative predictor within the collective data of The Cancer Genome Atlas, suggesting AdenoSig 
Strongly correlated

IFNG ICOS, TIGIT, TNFRSF9, CD80, CXCL10, CXCL9, CCR1, CD3G, PDCD1LG2, JAK2, STAT1, NCR1, RSAD2, CCR8, CD163, CTLA4, CD3D, CD3E, CCL5, CD247, PDCD1, CD8A, SIRPG, CD69, HLA-DOA, HLA-DQA1, HLA-DPA1, HLA-DRA, ITGAL, ITGB2, CD86, HAVCR2, PRDM1, CD28, SIGLEC1, CD4, CD33, CSF1R, IL10, TLR7, HLA-DMB, IDO1, KIR2DL4, CD38, LAG3, TBX21, KLRK1, LTA, STAT4, TNF, CXCR3, CD27, CD72, FOXP3, LAMP3, BTLA, HLA-DMA, HLA-DQB1, HLA-DRB5, HLA-DPB1, HLA-DRB1, CD40LG, HLA-DOB, HLA-DQA2, HLA-DQB2, IRF4, CD40, STAT2, IL1B CD14 CD244, CSF2RA, ICAM1, ITGAM, ITGAX, CD68, MICB, LY75, JAK1, STAT3, ISG20, CD79A, IL12B, KIR3DL2, KIR2DL3 KIR3DL1, ADAM8, IRF9, CCR6, HLA-A, HLA-B, HLA-C

CYTH2, NDUFA2, SLC9A3R2, ACTN4, EDNRB, ACTN2, VEGFA, IFNW1, IFNA21, IFNA14, IFNA 10, IFNA17 IFNA4, IFNA2, IFNA16, IFNA8, IFNA6, IFNA5, IFNA7, CEACAM8, IL17F, IL4, KRT20, SHH, CD24, VTCN1, MAGEH1, NCAM1, HMGB1, NECAB2, VAMP2, MST1R STAT5B, IL17A KIR3DL3 STAT6 ICOSLG, USP4 RORC, ST6GAL1, TNFRSF14, MICA, TYK2, CCL20, XBP1, TSNAX, ARG2, EPB41, SNAP23, IL13, CD22, IFNK IL5 ACTN3, IL 22 CX3CL1, IL23A A4GALT, LAYN TGFB2, TGFB3, ARG1, SMAD3, ADORA1, CD276, MME ADORA2B, TNFSF9, ADK, IFNA13, IFNA1, ADORA2A, ADA TNFRSF4, CD79B, IL3RA, KIR2DL1, KIR2DS4 CLEC4C, TLR9, CD19, FCER2, CD160, IL18, TNFRSF18, BCL6, GATA3, HSPA8, ACTN1, TIPARP, IL12A, NT5E, IL1A, FCGR3B, IFNB1, RORA, TNFSF4, TMEM173, CAV1, CD93, ADORA3, CD70, BATF3, IL6, ENTPD1, TGFB1

\section{Less correlated}

Figure 2 Heatmap of Pearson R coefficients between PD-L1 expression and immune target genes plus adenosine related genes by tumor type. Green = checkpoint targets; Red = adenosine related genes (dark red = targets under clinical investigation); Bold = other immunomodulatory genes.

as a poor risk, immunosuppressive feature, but one that is differentiated from IFN- $\gamma$ related signatures tied to antiPD1 response. Finally, in assessing the AdenoSig expression scores among the cancer types with the most clinical trial data thus far (NSCLC, melanoma, RCC, mCRPC), there does not appear to be a consistent pattern among the responding tumor types. ${ }^{84}$ This heterogenous data points to additional biologic pathways that will require investigation to more accurately predict response to A2AR blockade.

Supporting the potential biological relevance of the AdenoSig, McDermott et al independently assessed a "myeloid inflammatory" gene signature that was associated with immunosuppressive myeloid-related inflammation (CXCL1, 2, 3, 8, IL-6, PTGS2) in patients with RCG treated in a clinical trial of anti-VEGF and anti-PD-L1. ${ }^{85}$ This signature differed by only one gene as compared with AdenoSig and was associated with overall poor response. ${ }^{83} 85$ In tumors with high $\mathrm{T}$ cell infiltration and high myeloid inflammatory scores, anti-PD-L1 alone resulted in persistently poor outcomes; it was not until the combination of anti-PD-L1 plus VEGF blockade that outcomes were improved. The authors of the AdenoSig score also recognized this connection but observed that patients with AdenoSighi tumors had an inverse correlation with angiogenesis-related gene expression. Thus, it is hypothesized that anti-PD1/L1 plus A2AR blockade would be the optimal treatment modality for patients exhibiting elevated AdenoSig or myeloid inflammatory scores as opposed to antiangiogenesis therapy. Regardless, two independent groups identifying very similar genomic signatures associated with immunosuppression and response to immunotherapy is likely relevant. As shown in figure 3A, the tight correlation between the AdenoSig and myeloid inflammatory signatures likely indicates an underlying biology relevant for both VEGF and A2AR blockade.

Another genomic signature, the Adenosine Signaling Score (as opposed to AdenoSig), was developed by Sidders et $a l$ and comprises genes with expression correlated with A2AR signaling in human cancers (PPARG, CYBB, COL3A1, FOXP3, LAG3, APP, CD81, GPI, PTGS2, CASP1, FOS, MAPK1, MAPK3, CREB1) ${ }^{86}$ This score was directly correlated with adenosine concentration and significantly reduced in A2AR knockout models. Additionally, the Adenosine Signaling Score was inversely correlated with anti-PD1 response in a conglomerate of patients with NSCLC, HNSCC, and melanoma. ${ }^{87}$ As opposed to 

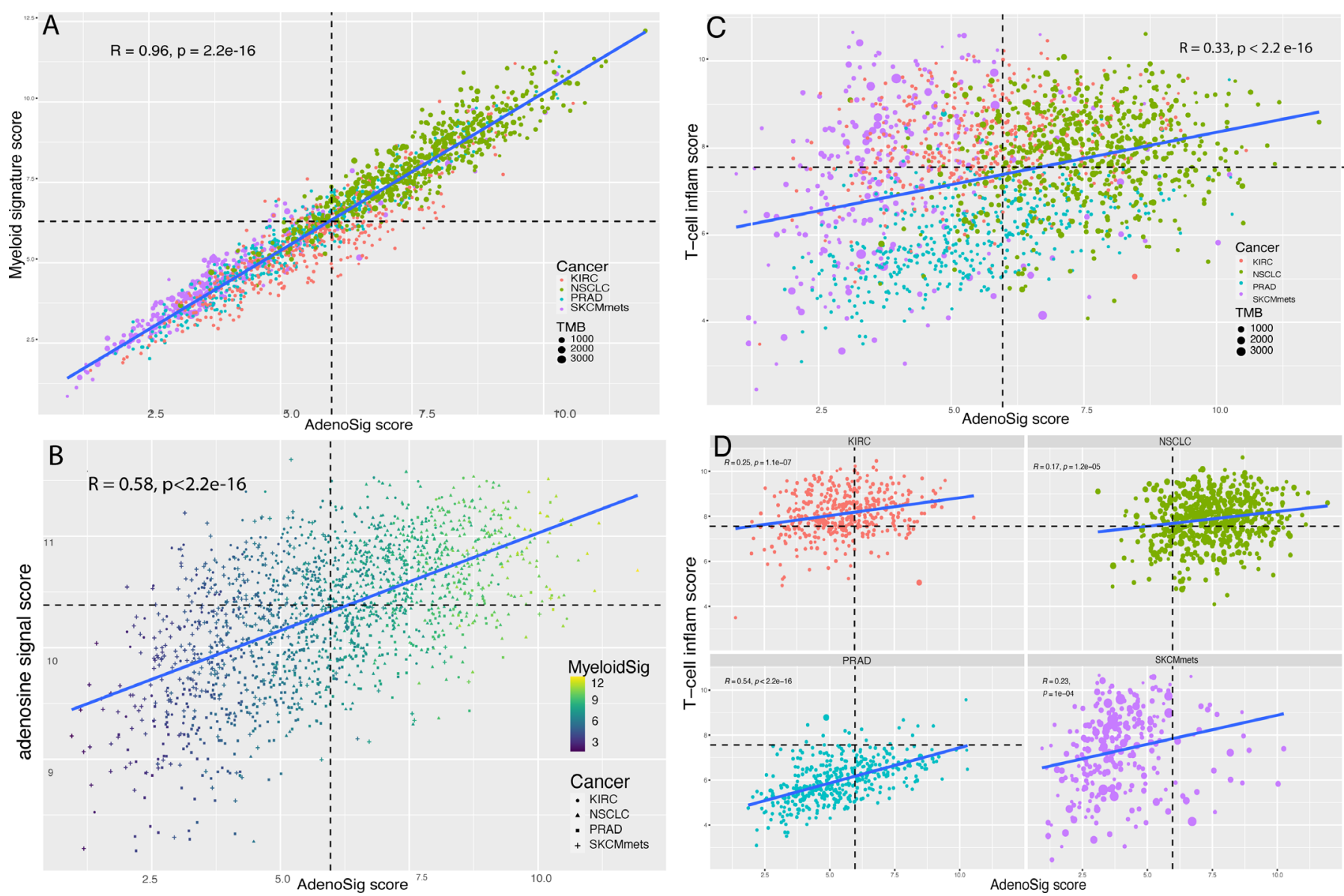

Figure 3 Correlation between the (A) AdenoSig and myeloid signature scores; (B) AdenoSig, adenosine signal, and myeloid signatures; (C \& D) AdenoSig and T cell inflamed signatures scores among RCC (KIRC), NSCLC, prostate (PRAD), and melanoma (SKCMmets) tumor samples from the TCGA consortium (see methods). KIRC, kidney renal cell carcinoma; NSCLC, non-small cell lung cancer; PRAD, prostate adenocarcinoma.

the checkpoint inhibitor response, this score was highly predictive of improved outcomes to A2AR blockade in a cohort of patients with mCRPC. ${ }^{88}$ In assessing all tumors within TCGA, the adenosine signaling signature has a wide range of expression; and as with AdenoSig, there does not appear to be a consistently elevated score among the cancer types best studied for response to A2AR inhibition (NSCLC, RCC, melanoma, mCRPC) ${ }^{86}$ Again, elucidation of additional biomarkers will be crucial for more accurate interpretation of this genomic signature moving forward.

Despite the AdenoSig and adenosine signaling scores only sharing one gene in common, they have a relatively high correlation among the four cancer types previously discussed (figure 3B). Thus, the biology behind the two signatures is likely related, and both scores might offer utility for clinical trial screening. Based on previously mentioned work, however, building a model including $\mathrm{T}$ cell-inflamed gene expression with these adenosine signatures will be crucial for optimizing outcomes with A2AR inhibitors. As seen in figure 3C, the T cell-inflamed and AdenoSig gene signatures are positively correlated, although modestly, denoting a subpopulation of Tinfl ${ }^{\text {hi }}$ / AdenoSig $^{\text {hi }}$ tumors that may be most relevant to target in the clinical setting. In separating these cancer types, nuanced characteristics are revealed (figure 3D). For example, prostate tumors have the highest correlation between Tinfl and AdenoSig scores, melanoma samples have lower overall AdenoSig scores but significantly higher TMB levels, and NSCLC appears to be most abundant in Tinfl ${ }^{\mathrm{hi}} /$ AdenoSighi ${ }^{\mathrm{hi}}$ tumors. Overall, these genetic signatures together with other biomarkers could help select individual tumor samples across various cancer types that may most benefit from adenosine pathway and checkpoint inhibitors.

In looking towards next steps in the field, certain clinical trials have already started to incorporate biomarkers into the patient selection process. For example, the clinical development of INCB106385 as an A2AR antagonist \pm anti-PD1 therapy will only recruit patients with cytotoxic $\mathrm{T}$ cell positive tumors, as measured by immunohistochemistry ${ }^{89}$ Another trial with ciforadenant $\pm \mathrm{a}$ tezolizumab reassessed response data based on the presence of tumor-infiltrating CD68 +myeloid cells, an effector cell for adenosine mediated immunosuppression (table 1A). Consistently, a significantly higher number of A2AR responders were found in the CD68 $+{ }^{\text {hi }}$ cohort as compared with the patients with CD68 $+{ }^{\text {lo }}$ tumors. ${ }^{90}$ While 
prudent use of these biomarkers is encouraging, further incorporation of the aforementioned adenosine-related and T cell-inflamed gene signatures will be an important step forward in developing clinical trials. Other future work will focus on combining multiple targets of the adenosine pathway (eg, HIF1-alpha, CD38, CD39, CD73, A2AR inhibitors), incorporating A2AR antagonists into earlier lines of therapy alongside PD1 or VEGF inhibitors, and combining novel immune-based therapies-as seen in an ongoing phase II clinical trial with PD1, TIGIT, and A2AR inhibition in PD-L1 ${ }^{\text {hi }}$ NSCLC. ${ }^{91}$

In conclusion, the adenosine pathway is a wellcharacterized mediator of immunosuppression in the TME. Various aspects of this pathway can be targeted with minimal toxicity, further adding to the clinical repertoire of immunostimulatory agents. While early trials have shown modest benefit with A2AR blockade, considerable work is now underway to assess combinatorial strategies with checkpoint inhibition and other immune-based therapies. Finally, the most successful patient outcomes may depend on advanced biomarkers and genomic signatures associated with both $\mathrm{T}$ cell-enriched tumors and the adenosine signaling pathway.

\section{METHODS: GENE EXPRESSION ANALYSIS, HEATMAP, AND CORRELATION PLOTS}

RNA-seq gene expression data (release February 4, 2015), preprocessed by the Broad Institute, was downloaded for 31 solid tumor types from TCGA. Note, diffuse large B-cell lymphoma, acute myeloid leukemia, and thymoma data were removed due to disproportionately elevated immune cell transcripts. Gene expression was quantified by RNA-Seq by Expectation Maximization algorithm and raw read counts were subsequently mapped to gene features. The count-based gene expression was normalized across all samples using the upper quartile method with subsequent $\log _{2}$ transformation. A total of 9508 tumor samples were included in the analysis. The tumor samples were filtered by non-T cell-inflamed, intermediate, and $\mathrm{T}$ cell-inflamed tumor groups using a previously defined 160-gene T cell-inflamed signature (Tinfl).$^{92}$ A list of 166 immune molecules involved in tumor-immune cell interaction along with 25 adenosine related genes were selected and correlated with PD-L1 (CD274) ${ }^{82}$ Pearson's correlation was computed between the gene expression of each immune molecule and $P D$ L1 for each tumor. These correlation values were used for hierarchical unsupervised clustering with Euclidean distance. Two distinct clusters were identified consisting of strongly correlated and less correlated genes used for heatmap construction.

For the correlation plots, a gene set enrichment analysis was performed for the Tinfl, AdenoSig, adenosine signal score, and myeloid gene signatures using expression data from the TCGA tumor types of interest. All analyses were performed using Bioconductor packages in R (V.4.0.3)
Twitter Aung Naing @AnaingMD, Riyue Bao @RiyueSunnyBao and Jason J. Luke @ jasonlukemd

Contributors RCA: wrote manuscript, original genomic analyses, compiled edits. BL: contributed preclinical work, manuscript edits. AN, LF: contributed preclinical and clinical work, manuscript edits. RB: original genomic analyses, manuscript edits. JJL: compiled clinical work/data, provided extensive manuscript edits, supervised design and implementation of manuscript.

Funding JJL acknowledges Department of Defense Career Development Award (W81XWH-17-1-0265), the Arthur J Schreiner Family Melanoma Research Fund, the J. Edward Mahoney Foundation Research Fund, Brush Family Immunotherapy Research Fund and Buffet Fund for Cancer Immunotherapy.

Competing interests RCA: None. RDL: Consultant for Astellas/Mitobridge; Inventor for "Methods for cancer and immunotherapy using prodrugs of glutamine analogs." US 10,842,763 which has been licensed to Dracen Pharmaceuticals. AN: Research funding: NCI, EMD Serono, Medlmmune, Healios Onc. Nutrition, Atterocor/ Millendo, Amplimmune, ARM0 BioSciences, Karyopharm Therapeutics, Incyte, Novartis, Regeneron, Merck, Bristol-Myers Squibb, Pfizer, CytomX Therapeutics, Neon Therapeutics, Calithera Biosciences, TopAlliance Biosciences, Eli Lilly, Kymab, PsiOxus, Arcus Biosciences, NeolmmuneTech, ImmuneOncia, Surface Oncology, Monopteros Therapeutics, BioNTech SE, Seven \& Eight Biopharma, and SOTIO Biotech AG, Immune Deficiency Foundation, Jeffery Modell Foundation and chao physician-scientist, and Baxalta. Advisory board: CytomX Therapeutics, Novartis, Genome \& Company, OncoSec KEYNOTE-695, Kymab, STCube Pharmaceuticals, and Deka Biosciences, Takeda, CSL, Behring, Horizon, and Pharming. Travel and accommodation expense: ARMO BioSciences. Spouse. LF: Research funding: Abbvie, Bavarian Nordic, Bristol Myer Squibb, Corvus, Dendreon, Janssen, Merck, and Roche/Genentech. Scientific advisor for: Actym, Allector, Astra Zeneca, Atreca, Bioalta, Bolt, Bristol Myer Squibb, Immunogenesis, Merck, Merck KGA, Nutcracker, RAPT, Scribe, Senti, Soteria, TeneoBio, and Roche/Genentech. RB: (all provisional) PCT/US15/612657 (Cancer Immunotherapy), PCT/US18/36052 (Microbiome Biomarkers for Anti-PD-1/PD-L1 Responsiveness: Diagnostic, Prognostic and Therapeutic Uses Thereof), PCT/US63/055227 (Methods and Compositions for Treating Autoimmune and Allergic Disorders). JJL: DSMB: Abbvie, Immutep; Scientific Advisory Board: (no stock) 7 Hills, Fstar, Inzen, RefleXion, Xilio (stock) Actym, Alphamab Oncology, Arch Oncology, Kanaph, Mavu, Onc.Al, Pyxis, Tempest; Consultancy with compensation: Abbvie, Alnylam, Avillion, Bayer, Bristol-Myers Squibb, Checkmate, Codiak, Crown, Day One, Eisai, EMD Serono, Flame, Genentech, Gilead, HotSpot, Kadmon, KSQ, Janssen, Ikena, Immunocore, Incyte, Macrogenics, Merck, Mersana, Nektar, Novartis, Pfizer, Regeneron, Ribon, Rubius, Silicon, Synlogic, Synthekine, TRex, Werewolf, Xencor; Research Support: (all to institution for clinical trials unless noted) AbbVie, Agios (IIT), Astellas, Astrazeneca, BristolMyers Squibb (IIT \& industry), Corvus, Day One, EMD Serono, Fstar, Genmab, Ikena, Immatics, Incyte, Kadmon, KAHR, Macrogenics, Merck, Moderna, Nektar, Next Cure, Numab, Pfizer (IIT \& industry) Replimmune, Rubius, Scholar Rock, Synlogic, Takeda, Trishula, Tizona, Xencor; Patents: (both provisional) Serial \#15/612,657 (Cancer Immunotherapy), PCT/US18/36052 (Microbiome Biomarkers for Anti-PD-1/PD-L1 Responsiveness: Diagnostic, Prognostic and Therapeutic Uses Thereof).

Patient consent for publication Not applicable.

Ethics approval This study does not involve human participants.

Provenance and peer review Not commissioned; externally peer reviewed.

Open access This is an open access article distributed in accordance with the Creative Commons Attribution Non Commercial (CC BY-NC 4.0) license, which permits others to distribute, remix, adapt, build upon this work non-commercially, and license their derivative works on different terms, provided the original work is properly cited, appropriate credit is given, any changes made indicated, and the use is non-commercial. See http://creativecommons.org/licenses/by-nc/4.0/.

\section{ORCID iDs}

Robert D. Leone http://orcid.org/0000-0002-1664-0075

Aung Naing http://orcid.org/0000-0002-4803-8513

Riyue Bao http://orcid.org/0000-0002-6105-1704

Jason J. Luke http://orcid.org/0000-0002-1182-4908

\section{REFERENCES}

1 Jenkins RW, Barbie DA, Flaherty KT. Mechanisms of resistance to immune checkpoint inhibitors. Br J Cancer 2018;118:9-16.

2 O'Donnell JS, Long GV, Scolyer RA, et al. Resistance to PD1/PDL1 checkpoint inhibition. Cancer Treat Rev 2017;52:71-81. 
3 Cronstein BN. Adenosine, an endogenous anti-inflammatory agent. J Appl Physiol 1994;76:5-13.

4 Takayama H, Trenn G, Sitkovsky MV. Locus of inhibitory action of cAMP-dependent protein kinase in the antigen receptortriggered cytotoxic T lymphocyte activation pathway. $J$ Biol Chem 1988;263:2330-6.

5 Wolberg G, Zimmerman TP, Hiemstra K, et al. Adenosine inhibition of lymphocyte-mediated cytolysis: possible role of cyclic adenosine monophosphate. Science 1975;187:957-9.

6 Allard B, Allard D, Buisseret L, et al. The adenosine pathway in immuno-oncology. Nat Rev Clin Oncol 2020;17:611-29.

7 Antonioli L, Blandizzi C, Pacher P, et al. Immunity, inflammation and cancer: a leading role for adenosine. Nat Rev Cancer 2013;13:842-57.

8 Antonioli L, Pacher P, Vizi ES, et al. CD39 and CD73 in immunity and inflammation. Trends Mol Med 2013;19:355-67.

9 Rankin EB, Giaccia AJ. The role of hypoxia-inducible factors in tumorigenesis. Cell Death Differ 2008;15:678-85.

10 Eltzschig HK, Ibla JC, Furuta GT, et al. Coordinated adenine nucleotide phosphohydrolysis and nucleoside signaling in posthypoxic endothelium: role of ectonucleotidases and adenosine A2B receptors. J Exp Med 2003;198:783-96.

$11 \mathrm{Li} \mathrm{J}$, Wang L, Chen X, et al. CD39/CD73 upregulation on myeloidderived suppressor cells via TGF- $\beta$-mTOR-HIF- 1 signaling in patients with non-small cell lung cancer. Oncoimmunology 2017;6:e1320011.

12 Ma S-R, Deng W-W, Liu J-F, et al. Blockade of adenosine A2A receptor enhances $C D 8^{+} T$ cells response and decreases regulatory T cells in head and neck squamous cell carcinoma. Mol Cancer 2017;16:99.

13 Fortin A, Harbour D, Fernandes M, et al. Differential expression of adenosine receptors in human neutrophils: up-regulation by specific Th1 cytokines and lipopolysaccharide. J Leukoc Biol 2006:79:574-85.

14 Ohta A, Sitkovsky M. Role of G-protein-coupled adenosine receptors in downregulation of inflammation and protection from tissue damage. Nature 2001;414:916-20.

15 Vijayan D, Young A, Teng MWL, et al. Targeting immunosuppressive adenosine in cancer. Nat Rev Cancer 2017;17:709-24

16 Borea PA, Gessi S, Merighi S, et al. Pharmacology of adenosine receptors: the state of the art. Physiol Rev 2018;98:1591-625.

17 Novitskiy SV, Ryzhov S, Zaynagetdinov R, et al. Adenosine receptors in regulation of dendritic cell differentiation and function. Blood 2008:112:1822-31.

18 Umemura N, Saio M, Suwa T, et al. Tumor-infiltrating myeloidderived suppressor cells are pleiotropic-inflamed monocytes/ macrophages that bear M1- and M2-type characteristics. J Leukoc Biol 2008;83:1136-44.

19 Ryzhov S, Novitskiy SV, Goldstein AE, et al. Adenosinergic regulation of the expansion and immunosuppressive activity of $\mathrm{CD} 11 \mathrm{~b}+\mathrm{Gr} 1+$ cells. J Immunol 2011;187:6120-9.

20 Mandapathil M, Hilldorfer B, Szczepanski MJ, et al. Generation and accumulation of immunosuppressive adenosine by human CD4+CD25highFOXP3+ regulatory T cells. J Biol Chem 2010;285:7176-86

21 Deaglio S, Dwyer KM, Gao W, et al. Adenosine generation catalyzed by CD39 and CD73 expressed on regulatory T cells mediates immune suppression. J Exp Med 2007;204:1257-65.

22 Raskovalova T, Huang X, Sitkovsky M, et al. Gs protein-coupled adenosine receptor signaling and lytic function of activated NK cells. J Immunol 2005;175:4383-91.

23 Young A, Ngiow SF, Gao Y, et al. A2AR adenosine signaling suppresses natural killer cell maturation in the tumor microenvironment. Cancer Res 2018;78:1003-16.

24 Haskó G, Cronstein BN. Adenosine: an endogenous regulator of innate immunity. Trends Immunol 2004;25:33-9.

25 Allard B, Cousineau I, Allard D, et al. Adenosine A2a receptor promotes lymphangiogenesis and lymph node metastasis. Oncoimmunology 2019;8:1601481.

26 Ramjiawan RR, Griffioen AW, Duda DG. Anti-angiogenesis for cancer revisited: is there a role for combinations with immunotherapy? Angiogenesis 2017;20:185-204

27 Haskó G, Csóka B, Németh ZH, et al. A(2B) adenosine receptors in immunity and inflammation. Trends Immunol 2009;30:263-70.

28 Zhou X, Zhi X, Zhou P, et al. Effects of ecto-5'-nucleotidase on human breast cancer cell growth in vitro and in vivo. Oncol Rep 2007:17:1341-6.

29 Serra S, Horenstein AL, Vaisitti T, et al. CD73-generated extracellular adenosine in chronic lymphocytic leukemia creates local conditions counteracting drug-induced cell death. Blood 2011;118:6141-52.
30 Mittal D, Sinha D, Barkauskas D, et al. Adenosine 2B receptor expression on cancer cells promotes metastasis. Cancer Res 2016;76:4372-82.

31 Koussémou M, Lorenz K, Klotz K-N. The A2B adenosine receptor in MDA-MB-231 breast cancer cells diminishes ERK1/2 phosphorylation by activation of MAPK-phosphatase-1. PLoS One 2018;13:e0202914.

32 Zhou Y, Chu X, Deng F, et al. The adenosine A2b receptor promotes tumor progression of bladder urothelial carcinoma by enhancing MAPK signaling pathway. Oncotarget 2017;8:48755-68.

33 Ohana G, Bar-Yehuda S, Barer F, et al. Differential effect of adenosine on tumor and normal cell growth: focus on the A3 adenosine receptor. J Cell Physiol 2001;186:19-23.

34 Ohta A, Gorelik E, Prasad SJ, et al. A2A adenosine receptor protects tumors from antitumor T cells. Proc Natl Acad Sci U S A 2006;103:13132-7.

35 Meng F, Guo Z, Hu Y, et al. CD73-derived adenosine controls inflammation and neurodegeneration by modulating dopamine signalling. Brain 2019;142:700-18.

36 Motawi TK, Sadik NAH, Hamed MA, et al. Potential therapeutic effects of antagonizing adenosine $A_{2 A}$ receptor, curcumin and niacin in rotenone-induced Parkinson's disease mice model. Mol Cell Biochem 2020;465:89-102.

37 Leone RD, Emens LA. Targeting adenosine for cancer immunotherapy. J Immunother Cancer 2018;6:57.

38 Waickman AT, Alme A, Senaldi L, et al. Enhancement of tumor immunotherapy by deletion of the A2A adenosine receptor. Cancer Immunol Immunother 2012;61:917-26.

39 Beavis PA, Milenkovski N, Henderson MA, et al. Adenosine receptor 2A blockade increases the efficacy of anti-PD-1 through enhanced antitumor T-cell responses. Cancer Immunol Res 2015;3:506-17.

40 Stagg J, Divisekera U, Duret $\mathrm{H}$, et al. CD73-deficient mice have increased antitumor immunity and are resistant to experimental metastasis. Cancer Res 2011;71:2892-900.

41 Wang L, Zhou X, Zhou T, et al. Ecto-5'-nucleotidase promotes invasion, migration and adhesion of human breast cancer cells. $J$ Cancer Res Clin Oncol 2008;134:365-72.

42 Leone RD, Sun I-M, Oh M-H, et al. Inhibition of the adenosine A2a receptor modulates expression of $\mathrm{T}$ cell coinhibitory receptors and improves effector function for enhanced checkpoint blockade and ACT in murine cancer models. Cancer Immunol Immunother 2018;67:1271-84.

43 Ngiow SF, Young A, Jacquelot N, et al. A threshold level of intratumor CD8+ T-cell PD1 expression dictates therapeutic response to antiPD1. Cancer Res 2015;75:3800-11.

44 Allard B, Pommey S, Smyth MJ, et al. Targeting CD73 enhances the antitumor activity of anti-PD-1 and anti-CTLA-4 mAbs. Clin Cancer Res 2013;19:5626-35.

45 Sun X, Wu Y, Gao W, et al. CD39/ENTPD1 expression by CD4+Foxp3+ regulatory T cells promotes hepatic metastatic tumor growth in mice. Gastroenterology 2010;139:1030-40.

46 Perrot I, Michaud H-A, Giraudon-Paoli M, et al. Blocking antibodies targeting the CD39/CD73 immunosuppressive pathway unleash immune responses in combination cancer therapies. Cell Rep 2019;27:2411-25.

47 Young A, Ngiow SF, Barkauskas DS, et al. Co-Inhibition of CD73 and A2aR adenosine signaling improves anti-tumor immune responses. Cancer Cell 2016;30:391-403.

48 Ribas A, Hodi FS, Callahan M, et al. Hepatotoxicity with combination of vemurafenib and ipilimumab. N Engl J Med 2013;368:1365-6.

49 Minor DR, Puzanov I, Callahan MK, et al. Severe gastrointestinal toxicity with administration of trametinib in combination with dabrafenib and ipilimumab. Pigment Cell Melanoma Res 2015;28:611-2.

50 Young A, Ngiow SF, Madore J, et al. Targeting adenosine in BRAFmutant melanoma reduces tumor growth and metastasis. Cancer Res 2017:77:4684-96.

51 Vaupel P, Multhoff G. Fatal alliance of hypoxia-/HIF-1 $\alpha$-driven microenvironmental traits promoting cancer progression. Adv Exp Med Biol 2020:1232:169-76.

52 Hatfield SM, Kjaergaard J, Lukashev D, et al. Immunological mechanisms of the antitumor effects of supplemental oxygenation. Sci Transl Med 2015;7:277ra30.

53 Kroemer G, Galluzzi L, Kepp O, et al. Immunogenic cell death in cancer therapy. Annu Rev Immunol 2013;31:51-72.

54 Michaud M, Martins I, Sukkurwala AQ, et al. Autophagy-dependent anticancer immune responses induced by chemotherapeutic agents in mice. Science 2011;334:1573-7.

55 Wang L, Londono LM, Cowell J, et al. Targeting adenosine with adenosine deaminase 2 to inhibit growth of solid tumors. Cancer Res $2021 ; 81: 3319-32$ 
56 Cekic $\mathrm{C}$, Linden J. Adenosine A2A receptors intrinsically regulate CD8+ T cells in the tumor microenvironment. Cancer Res 2014;74:7239-49.

57 Wennerberg E, Spada S, Rudqvist N-P, et al. CD73 blockade promotes dendritic cell infiltration of irradiated tumors and tumor rejection. Cancer Immunol Res 2020;8:465-78.

58 Yu M, Guo G, Huang L, et al. CD73 on cancer-associated fibroblasts enhanced by the $A_{2 B}$-mediated feedforward circuit enforces an immune checkpoint. Nat Commun 2020;11:515.

59 Chen S, Akdemir I, Fan J, et al. The expression of adenosine $\mathrm{A} 2 \mathrm{~B}$ receptor on antigen-presenting cells suppresses $\mathrm{CD} 8^{+} \mathrm{T}-$ cell responses and promotes tumor growth. Cancer Immunol Res 2020;8:1064-74.

60 Porta C, Consonni FM, Morlacchi S, et al. Tumor-derived prostaglandin E2 promotes p50 NF-kB-dependent differentiation of monocytic MDSCs. Cancer Res 2020;80:2874-88.

61 Böttcher JP, Bonavita E, Chakravarty P, et al. NK cells stimulate recruitment of cdc1 into the tumor microenvironment promoting cancer immune control. Cell 2018;172:1022-37.

62 Hong DS, Parikh A, Shapiro Gl, et al. First-in-human phase I study of immunomodulatory E7046, an antagonist of $\mathrm{PGE}_{2}$-receptor E-type 4 (EP4), in patients with advanced cancers. $J$ Immunother Cancer 2020;8:e000222.

63 Horenstein AL, Chillemi A, Quarona V, et al. NAD+-metabolizing ectoenzymes in remodeling tumor-host interactions: the human myeloma model. Cells 2015;4:520-37.

64 Gao L, Liu Y, Du X, et al. The intrinsic role and mechanism of tumor expressed-CD38 on lung adenocarcinoma progression. Cell Death Dis 2021:12:680.

65 Kato K, Nishimasu H, Oikawa D, et al. Structural insights into cGAMP degradation by ecto-nucleotide pyrophosphatase phosphodiesterase 1. Nat Commun 2018;9:4424.

$66 \mathrm{Ng} \mathrm{HHM}$, Lee RY, Goh S, et al. Immunohistochemical scoring of CD38 in the tumor microenvironment predicts responsiveness to anti-PD-1/PD-L1 immunotherapy in hepatocellular carcinoma. $\mathrm{J}$ Immunother Cancer 2020;8.

67 Krejcik J, Casneuf T, Nijhof IS, et al. Daratumumab depletes CD38+ immune regulatory cells, promotes T-cell expansion, and skews T-cell repertoire in multiple myeloma. Blood 2016;128:384-94.

68 Horenstein AL, Bracci C, Morandi F, et al. CD38 in adenosinergic pathways and metabolic re-programming in human multiple myeloma cells: in-tandem insights from basic science to therapy. Front Immunol 2019;10:760.

69 Linette GP, Carreno BM. Tumor-infiltrating lymphocytes in the checkpoint inhibitor era. Curr Hematol Malig Rep 2019;14:286-91.

70 Gajewski TF, Corrales L, Williams J, et al. Cancer immunotherapy targets based on understanding the T cell-inflamed versus non-T cell-inflamed tumor microenvironment. Adv Exp Med Biol 2017;1036:19-31.

71 Luke JJ, Ott PA. PD-1 pathway inhibitors: the next generation of immunotherapy for advanced melanoma. Oncotarget 2015;6:3479-92.

72 Cristescu R, Mogg R, Ayers M, et al. Pan-tumor genomic biomarkers for PD-1 checkpoint blockade-based immunotherapy. Science 2018;362 doi:10.1126/science.aar3593

73 Spranger S, Spaapen RM, Zha Y, et al. Up-regulation of PD-L1, IDO, and $\mathrm{T}$ (regs) in the melanoma tumor microenvironment is driven by CD8(+) T cells. Sci Trans/ Med 2013;5:200ra116.

74 Ayers M, Lunceford J, Nebozhyn M, et al. IFN- $\gamma$-related mRNA profile predicts clinical response to PD-1 blockade. J Clin Invest 2017:127:2930-40.

75 Bendell JC, LoRusso P, Overman MJ, et al. Safety and efficacy of the anti-CD73 monoclonal antibody (mAb) oleclumab \pm durvalumab in patients (pts) with advanced colorectal cancer (CRC), pancreatic ductal adenocarcinoma (PDAC), or EGFR-mutant non-small cell lung cancer (EGFRm NSCLC). JCO 2021;39:9047.

76 OncologyPRO. COAST: an open-label, randomised, phase II platform study of durvalumab alone or in combination with novel agents in patients with locally advanced. Available: https://oncologypro.esmo. org/meeting-resources/esmo-congress-2021/coast-an-open-labelrandomised-phase-ii-platform-study-of-durvalumab-alone-or-incombination-with-novel-agents-in-patients-with-locally-advanced [Accessed 21 Sep 2021].

77 Kim D-W, Kim S-W, Camidge DR. Abstract CT163: CD73 inhibitor oleclumab plus osimertinib for advanced EGFRm NSCLC: first report of a phase 1b/2 study. Am Assoc Cancer Res 2021:CT163.

78 Chen L, Diao L, Yang Y, et al. CD38-mediated immunosuppression as a mechanism of tumor cell escape from PD-1/PD-L1 blockade. Cancer Discov 2018;8:1156-75.

79 Shen C, Kaelin WG. The VHL/HIF axis in clear cell renal carcinoma. Semin Cancer Biol 2013;23:18-25.

$80 \mathrm{Wu}$ J, Wang Y-C, Xu W-H, et al. High expression of CD39 is associated with poor prognosis and immune infiltrates in clear cell renal cell carcinoma. Onco Targets Ther 2020;13:10453-64.

81 Lee $\mathrm{JH}$, Elly C, Park Y, et al. E3 ubiquitin ligase VHL regulates hypoxia-inducible factor- $1 \alpha$ to maintain regulatory $T$ cell stability and suppressive capacity. Immunity 2015;42:1062-74.

82 Trujillo JA, Sweis RF, Bao R, et al. T cell-inflamed versus non-T cellinflamed tumors: a conceptual framework for cancer immunotherapy drug development and combination therapy selection. Cancer Immunol Res 2018;6:990-1000.

83 Fong L, Hotson A, Powderly JD, et al. Adenosine 2A receptor blockade as an immunotherapy for treatment-refractory renal cell cancer. Cancer Discov 2020;10:40-53.

84 Willingham SB, Hotson AN, Miller RA. Targeting the A2AR in cancer; early lessons from the clinic. Curr Opin Pharmacol 2020;53:126-33.

85 McDermott DF, Huseni MA, Atkins MB, et al. Clinical activity and molecular correlates of response to atezolizumab alone or in combination with bevacizumab versus sunitinib in renal cell carcinoma. Nat Med 2018;24:749-57.

86 Sidders B, Zhang P, Goodwin K, et al. Adenosine signaling is prognostic for cancer outcome and has predictive utility for immunotherapeutic response. Clin Cancer Res 2020;26:2176-87.

87 Prat A, Navarro A, Paré L, et al. Immune-related gene expression profiling after PD-1 blockade in non-small cell lung carcinoma, head and neck squamous cell carcinoma, and melanoma. Cancer Res 2017;77:3540-50.

88 Lim EA, Bauer TM, Patel MR, et al. A phase I, open-label, multicenter study to assess the safety, pharmacokinetics, and preliminary antitumor activity of AZD4635 both as monotherapy and in combination in patients with advanced solid malignancies: results from prostate cancer patients (NCT02740985). JCO 2020;38:5518.

89 INCB106385 alone or in combination with immunotherapy in advanced solid tumors. Available: https://clinicaltrials.gov/ct2/show/ NCT04580485 [Accessed 8 Sep 2021].

90 Voss $\mathrm{MH}$, Hotson AN, Willingham S, et al. CD68+ tumor-associated myeloid cells as the target of adenosine-induced gene products and predictor of response to adenosine blockade with ciforadenant (cifo) in renal cell cancer (RCC). JCO 2020;38:5025.

91 Study to evaluate monotherapy and combination immunotherapies in participants with PD-L1 positive non-small cell lung cancer. Available: https://clinicaltrials.gov/ct2/show/NCT04262856 [Accessed 8 Sep 2021].

92 Spranger S, Luke JJ, Bao R, et al. Density of immunogenic antigens does not explain the presence or absence of the T-cell-inflamed tumor microenvironment in melanoma. Proc Natl Acad Sci U S A 2016;113:E7759-68. 